\title{
Likes, Comments, and Follow Requests: The Instagram User Experiences of Young Muslim Women in the Netherlands
}

\author{
Lale Mahmudova \\ Research Assistant, Erasmus School of History Culture and Communication, \\ Erasmus University Rotterdam, Rotterdam, Netherlands \\ lale.mahmudovarg94@gmail.com \\ Giulia Evolvi \\ Lecturer, Erasmus School of History Culture and Communication, Erasmus \\ University Rotterdam, Rotterdam, Netherlands \\ evolvi@eshcc.eur.nl
}

\begin{abstract}
Young Dutch Muslim women often lead complex existences: on the one hand, they may be considered "other" to European culture and expected to conform to so-called Western values; on the other hand, they can be subject to scrutiny within their cultural and religious communities. This article explores young Dutch Muslim women's online practices by focusing on Instagram. By discussing the theories of third spaces (Bhabha, 1994; Pennington, 2018b) and composite habitus (Bourdieu, 199o; Waltorp, 2015), we investigate the following questions: How do young Dutch Muslim women use Instagram? What are the opportunities and constraints that they face when using Instagram? Through qualitative interviews, we discovered that Instagram helps young Dutch Muslim women express their identity in their own terms, but it presents negative aspects connected with privacy and surveillance. We then discuss the need not to generalize Muslim women's experiences and instead to consider their selective use of Instagram and heterogeneity within Islam.
\end{abstract}

\section{Keywords}

Islam - Instagram - the Netherlands - Internet - women - third space - composite habitus 
Islam is often considered as "other" to European culture and deemed somehow incompatible with democratic and secular values (Asad, 2003). These narratives are visible in the Netherlands, a country whose society is increasingly divided along religious and ethnic lines. The Dutch population is traditionally separated between "Autochtoon," people whose parents are both born in the Netherlands, and "Allochtoon," people who have at least one parent born abroad (Doomernik, 2017). Because the term Allochtoon is rooted in colonial practices and came to be negatively connoted within Dutch society, it was officially changed in 2016 to "people with a migration background," divided into "Western migrants" and "non-Western migrants," with the latter making up $14 \%$ of the population (СBS, 2020). However, far-right and xenophobic actors continue to use Allochtoon specifically to marginalize Muslims (van Sterkenburg et al., 2019). In this context, women may be further marginalized because of their religious belonging, their ethnicity, and their gender, especially if they wear a veil. Hence, the difficulties of Dutch Muslim women, who make up 5\% of the female population (Schmeets, 2018), are twofold: on the one hand, they may be considered "other" to European culture and expected to conform to so-called Western values; on the other hand, they can be subject to scrutiny within Muslim communities and are expected to follow certain religious and cultural norms (Leurs et al., 2020).

The Internet may offer a space for young Dutch Muslim women to express themselves relatively freely, going against stereotypes and deciding what kind of visibility they wish to publicly perform (Vis et al., 2011). Instagram, in particular, provides young women with a range of opportunities to create visual narratives and exercise agency of their own representation (Ross, 2019), as well as to gain popularity and develop businesses (van Driel \& Dumitrica, 2020). Previous studies often focused on Muslim women's use of social networks by analyzing the narratives of influencers or fashion icons (Wheeler, 2014; Peterson, 2020). We would argue that even if influencers perform important cultural work in normalizing and diffusing a certain image of Islam, there is also a need to analyze the everyday digital practices of Muslim women who are not Internet celebrities and who may not subscribe to certain fashion norms. For some of these women, Instagram may offer opportunities for self-representation, but it can also become a tool for scrutiny and surveillance from their own families and communities of belonging. Therefore, we explore the following questions: How do young Dutch Muslim women use Instagram? What are the opportunities and constraints that they face when using Instagram?

In the first section of this article, we employ the notion of hybrid identities and third spaces (Bhabha, 1994; Pennington, 2018) and the concept of habitus (Bourdieu, 1990; Waltorp, 2015, 2020) to describe how some young Dutch 
Muslim women may use Instagram as a venue to performatively create a certain image of the self. The first author of this article is herself a Dutch Muslim woman from an immigrant background, and this gave her the opportunity to recruit suitable interviewees for the research and personally understand and relate to their experiences. She performed semi-structured interviews asking participants about their religious identities and their use of Instagram, as described in the second section. The third section describes the results of the study. The interviews show that Dutch Muslim women are often aware of the difficulties of expressing hybrid identities. Instagram helps them counteract stereotypes about Islam and follow inspirational accounts of other Muslims, but many interviewees also feel that there are pictures they should not post on the platform. In conclusion, we discuss the need to employ the notions of composite habitus and third spaces without generalizing Muslim women's experiences, but consider their selective use of Instagram and focus on their different approaches in using Instagram.

\section{Hybrid Identities, Online Third Spaces, and Composite Habitus}

Young Dutch Muslim women use the Internet to discuss their religiosity and its impact on their everyday lives, and their narratives show complex subjectivities (Midden \& Ponzanesi, 2013). Identities, and in particular the identities of people with a migrant background, are fluid and continuously evolving, involve adaptations to surrounding environments, and may be conditioned by social control (Prokopiou et al., 2012). Multicultural cities, as happens in many areas of the Netherlands, can host religious identities expressed through material practices, architecture, and urban imaginaries (Becci et al., 2017). These processes lead to what Bhabha (1994) defines as "third space," a term that describes the post-colonial settings as performative venues that exist between the culture of the colonizer and the experience of the colonized. Bhabha's conceptualization of third spaces is useful to go beyond the exoticization of so-called non-Western cultures and to understand how hybrid identities are parts of the evolution and encounters of different identity traits. When it comes to Dutch Muslim women, they often perform cultural work in negotiating their culture and religious belonging within the Dutch context, thus opening up new venues to form hybrid identities.

The Internet can offer opportunities for people to perform complex and nuanced yet coherent identities (Szulc, 2019). In particular, members of minority groups can benefit from the public character of the Internet and, at the same time, choose to create closed profiles to safeguard their privacy (Ross, 
2019). When it comes to Muslims living in non-Muslim countries, previous academic scholarship has shown how the Internet can function as a space to negotiate religious identities and help Muslim women become narrators of their own stories (Kavakci \& Kraeplin, 2016; Peterson, 2016; Waninger, 2015). Boy, Uitermark, and Wiersma (2018) explore the hashtag \#hijabfashion and discover that Muslim sartorial practices exist across global networks but are also based on local centers that become relevant for Islamic fashion, such as the Dutch city of Rotterdam. In this case, digital media practices serve as "countrepublics" where hijab fashion is used to negotiate private, political, and religious meanings.

Scholars have used the notion of "hybridity" to describe young Muslims' usage of the Internet (Evolvi, 2017). Female bloggers and YouTubers can, indeed, use the Internet to create "hybrid Muslim subjectivities" (Echchaibi, 2013) and articulate "hybrid languages" (Wheeler, 2014) to counteract stereotypes about Islam and show that their religion is compatible with so-called Western values and secularism. As Pennington (2018) writes, the opportunities offered by the Internet to articulate hybrid Muslim identities can generate third spaces. In this respect, Bhabha's (1994) third space is reimagined as a venue between online and offline practices that allows people to creatively discuss and perform their religiosity by combining elements of different cultures, in a way that would not be possible without the Internet. Online third spaces can potentially be subversive of hegemonic rules and help members of minorities (such as Muslims in Europe) change mainstream narratives about their communities of belonging (Hoover \& Echchaibi, n.d.).

However, notwithstanding the opportunities for identity articulation offered by the Internet, there are also constraints that Muslim women may face in using digital media. While the aforementioned studies often explore the narratives of bloggers, YouTubers, and hijabi influencers, Muslim women who are not Internet personalities and do not necessarily wear a veil might have different experiences. Peterson (2020) notes that highly visible platforms such as Instagram may put users under the neoliberal pressure of performing a perfect image. On social media, Muslim women often feel that they need to appear modest and pious without giving the idea of being oppressed by their religion. This tension is explored by Waltorp (2015), who, in studying the Internet use of young Muslim women living in Copenhagen's social housing areas, asks how they can simultaneously respond to the expectations of their families, friends, and the broader Danish society (p. 559).

In addressing this question, Waltorp explains that Muslim women often feel scrutinized by family, neighbors, and community members. Smartphones could offer these young women a venue for intimate and secret relations and 
enhance their interpersonal connections, becoming an integral part of their world (Waltorp, 2020). However, publicly visible online profiles also come with the imperative of conforming to certain expectations. In the study, Waltorp introduces the notion of "composite habitus" to describe how the cultural and religious background of Muslim women contributes to their behaviors, ideologies, and identity expressions. Composite habitus draws from Bourdieu's (1990) conceptualization of dispositions through which individuals adapt to a social structure. The notion of composite habitus helps in understanding how Muslim women's relation to the future is determined by present practices, as well as the social conditions and power structures they experience. It also describes how Muslim women's habitus results in behaviors and identity performances that may be in contradiction with each other. Drawing from Waltorp's $(2015,2020)$ concept of composite habitus, we also argue that Dutch Muslim women's digital practices need to be understood in their complexity by considering the power relations of gender, ethnicity, and religiosity that they experience.

The notion of composite habitus is useful to explain how Muslim women use the Internet to make hybrid identities visible. Women are not only conditioned by the specific dispositions of their social position but also actively negotiate how they wish to perform their identities in given settings. Therefore, we explore the use of Instagram by young Dutch Muslim women by considering the Internet as potentially creating a third space where behaviors, beliefs, and life patterns that are conditioned by composite habitus can be discussed and made visible. We focus on the strategies that Muslim women employ with respect to both the opportunities and the constraints of Instagram. Hence, we chose not to focus on Internet narratives or social media influencers but rather to directly approach Muslim women and collect their experiences and strategies in their everyday Internet use.

\section{Exploring Dutch Muslim Women Digital Practices}

To explore how young Dutch Muslim women use social networks, semi-structured interviews were performed. This method allows direct communication with the subjects of the study and offers possibilities for clarifications and follow-up questions (Wethington \& McDarby, 2015). By performing interviews with women who may have private accounts or refrain from posting certain types of pictures, we were able to discover media practices, strategies, and life experiences that are largely invisible in a digital ethnography or a textual analysis of media narratives. Moreover, interviews allowed the 
participants to decide how they wanted to narrate their stories and opinions, and this addresses an academic gap as it is a method rarely used in the field of Islam and digital media (Hashmi et al., 2020). The sample was selected based on four criteria: first, participants should self-identify as Muslim women; second, they needed to be between 18 and 27 years old; third, they had to be from the Randstad area in the Netherlands; and, fourth, we chose women who were Instagram users.

The age range has been chosen because it includes adult women who are digital natives, meaning that they have been familiar with the Internet since childhood (Bittman et al., 2011). Moreover, young Muslim women are more likely to experience what we defined as "hybrid identities" in the previous section because they usually need to negotiate religious and cultural traditions of their countries of origin within the Dutch society where they study or work (Frisina, 2010). We recruited participants from the Randstad area, which includes the four big cities of Amsterdam, The Hague, Rotterdam, and Utrecht and the surrounding areas, and which is highly multicultural: in 2019, the Dutch statistics bureau revealed that nearly $55 \%$ of all citizens of the Hague and Amsterdam, $52 \%$ of all citizens from Rotterdam, and $35 \%$ of all citizens of Utrecht were from a non-Western immigrant background (CBS, 2020. As a result, this is an area with great religious diversity, where young Muslims can find more opportunities to experience various cultural and religious practices and imaginaries (Knott et al., 2016). The aforementioned research by Waltorp (2015; 2020) in Copenhagen, similar to the Randstad in hosting communities with migration backgrounds, shows that young women living in these environments can be subjected to greater scrutiny from their communities of belonging. We chose to focus on Instagram because it is a mobile phone app that allows sharing content with minimum effort. By embedding pictures, videos, and stories, and offering the ability to like and comment on other users' content, Instagram is a highly visual app that is appealing to young people and permits playfully showing various facets of one's identity. It allows users to gain popularity by becoming influencers who financially profit from the public nature of the app by using their platforms to advertise products (Blystone, 2020).

\section{Methodology: Recruitment and Interviews}

Participants were recruited through purposive and snowball sampling on social media. The first author of this article, who performed the interviews, is also a Dutch woman from the Randstad area and could find participants through posting announcements on her personal networks. Subsequently, she also asked respondents to indicate other possible participants that fit the sampling criteria. After conducting three pilot interviews, the first author collected 
a sample of twelve Muslim women from Moroccan, Egyptian, Bosnian, Pakistani, Turkish, and Azerbaijani backgrounds. The women were all born in the Netherlands or moved to the country at a young age, so the interviews were performed in Dutch and quotes translated to English for this article. In the sample, three of the women choose to wear a veil. The women are students or young professionals and have various relationship statuses, as some are single, others engaged or dating, and one is married. Seven of the respondents have private Instagram accounts, and one only uses the account to follow other people rather than posting pictures, but they all employ the app. Ethics approval for the study was granted by the Ethics Review Board of [removed for anonymity], and the names used in the article are nicknames that the interviewees chose to protect their privacy.

The interviews lasted between 45 minutes and 1.5 hours. Due to CoviD-19 restrictions, interviews were performed through Internet platforms such as Skype and Zoom. Because the participants all are digital natives and have access to technology, as they are Instagram users, performing the interviews online did not pose a problem. While online interviews may be less spontaneous and make it more difficult to read body language, participants could be more encouraged to talk about private topics such as religion and family life from the comfort of their personal spaces (Hanna, 2012). The use of the webcam allowed the participants' reactions to be seen and made it easier to ask follow-up questions or intervene with clarifications. Furthermore, because the interviewer is also a Dutch Muslim woman, she understands cultural codes and managed to create a sense of comfort and safety during the interview by sharing her positionality and stressing her non-judgmental attitude.

The first author prepared a list of questions for the semi-structured interviews based on the three pilot interviews and existing literature on Muslim hybrid identities, third spaces, and composite habitus, as analyzed in the previous section. The interviews were divided into three parts: (1) questions about personal life, which did not specifically focus on Internet use but allowed the interviewees to elaborate on their experience of being a Muslim woman in the Netherlands; (2) questions about Internet use, with a focus on Instagram; and (3) experiences in using Instagram, including perceived constraints and opportunities connected to the app. While this article's data are based on the interviews, the first author also became familiar with the interviewees' accounts after obtaining permission to follow them. Inspired by the principles of digital ethnography (Postill \& Pink, 2012), this process helped to create interview questions and better understand the data during the analysis. The interviews were transcribed and coded with Atlas.ti. A thematic analysis of the interview data revealed that Muslim women describe their everyday 
experiences in terms of religious and cultural belonging, and that a platform such as Instagram can help them express their identity in their own terms, even if it presents sometimes negative aspects.

\section{Results: Muslim Identities and Instagram Images}

The interviews revealed that young Dutch Muslim women experience complex feelings when it comes to describing their own lives, and that digital practices can help negotiate their behaviors and visibility. We will, first, describe how these women narrate their religious and ethnic identities. Then, we will show how Instagram can positively connect people to certain forms of religiosity and counteract stereotypes. Lastly, we will explore the interviewees' concerns about Instagram in relation to privacy and surveillance.

\section{Best of Both Worlds: Adaptations, Identities, and Muslim Experiences in the Netherlands}

The women interviewed as part of this study described both their religion and their cultural belonging as important parts of their upbringing and everyday lives. For instance, the majority of them reported that Islam influences their personal decisions and behaviors, such as not drinking alcohol, eating halal food, fasting during Ramadan, reading the Quran, dressing modestly, or wearing a hijab. Many respondents also described their affiliation to Islam as something that is not only visible or connected to material practices but also internalized as a structuring guide to moral behavior. Indeed, they said that being Muslim made them be kind to others, give money to charities, feel inner peace, and establish a personal relationship with God. Ethnicity and cultural belonging were often mentioned together with religion, and several of these women explained the need to constantly negotiate between different lifestyles:

I think it can perfectly be both. It's not a 50/50 things, one cannot express it in numbers. I feel at home here, and when I am in Egypt, I also feel at home there. On the other hand, over there, sometimes you get comments like "oh you're too Dutch," and then here you get comments like "oh you're too Egyptian." It's never really enough. And that used to be a struggle, at first, like, who am I? especially in high school I had an identity crisis, like, where do I belong? I do not belong anywhere. But now, now I have accepted that I am both. Both cultures complement me in my personality, and there is nothing wrong with being both. You just get the best out of both cultures. (FAYZA, 24 YEARS OLD, THE HAGUE) 
Fayza explains that her ability to feel at home in different cultures is marked by certain outside expectations: people would say that she is "too Dutch" or "too Egyptian," as if she should conform to certain behavioral patterns depending on the circumstances she finds herself in. This seems to be an impossible conundrum, because identities cannot be expressed in numbers, as Fayza says, and people raised between different cultural and religious environments inevitably experience a certain degree of hybridity. Nevertheless, this quote shows that Fayza successfully came to terms with her identity, and she can say that she gets "the best of both cultures." Other interviews similarly showed that young Muslim women treasure their complex personal histories and their multicultural backgrounds.

However, not all interviewees have the same positive experiences when it comes to negotiating their identities and conforming to certain Dutch social and cultural norms. If, for some women, this can represent an opportunity and an advantage, for others the need for adaptation can be an "exhausting" survival mechanism within Dutch society (Maryam, 23 years old, Rotterdam). In some cases, interviewees reported feeling discriminated against by questions about their hijabs during job interviews, teachers who marginalized them in the classroom, or people questioning their belonging to Dutch culture because of their appearance and religion. Many respondents encountered microaggressions, sometimes disguised as compliments, as in the case of Sara:

When I say that I am Pakistani, I used to get weird responses to that, like "oh you are pretty for a Pakistani," comments like that. And I used to not think about it, but now I think that is really an ugly thing to say. What do you mean to say? That Pakistanis can't be beautiful? (SARA, 26 YEARS OLD, ROTTERDAM)

This quote shows how apparently innocuous exchanges can be painful for young women. Such remarks make Sara implicitly aware that certain physical traits are considered more attractive than others. In particular, this points to a widespread conception that beauty and attraction are associated with fairer skin and "Western" appearance, often reinforced by media representations, beauty pageants, and cosmetic companies (Kumara \& Jayawardhana, 2018; Silvestrini, 2020). This racist notion of beauty can further enhance the idea that non-white people are "other" to Dutch and European society, to the point of being surprised that someone from Pakistan is "pretty." Hence, interviewees that report negative remarks about their appearance have darker skin tone and/ or they wear a hijab. This shows how belonging is not only connected to the ability to "integrate" with Dutch or European culture, but is also conditioned by 
skin color and garments, as Islamophobia tends to be experienced more heavily by women who wear hijabs (Allen, 2015). This appearance-privilege, which allows white or white-passing women to be more easily accepted than others, points to a problematic racist aspect of Dutch (and, one may say, European) society, which tends to still consider visibly "Allochtoon" people as "other" to its values and norms (van Sterkenburg et al., 2019).

The complexity of Dutch Muslim women's experiences, both positive and negative, often makes them question their values and habits. The notion of composite habitus (Waltorp, 2015, 2020) is useful to understand these dynamics where women both are conditioned by physical and cultural marks and also consciously perform a certain type of identity traits to adapt to different circumstances. In particular, for some of the interviewees, there is a difference between their culture and ethnicity, and their religion: Islam is considered as a universal force that brings people together, a faith that people consciously choose to practice. This is evident in the words of Bella, who says: "Your ethnicity, whether you are Dutch, Moroccan, Japanese, it does not matter. So, being a part of a societal group that is so big: Islam, the Muslims, it gives you a sense of fulfilment" (Bella, 25 years old, Hoofddorp). While these women cannot choose their cultural background and appearance, they can decide whether they want to practice Islam, and under which terms. In the case of Bella, Islam is a positive force she chooses to practice to gain a sense of fulfilment. Therefore, many of the interviewees said that they make efforts to self-educate themselves about Islam by reading and analyzing the Quran and through critical conversations with fellow Muslims. The Internet plays the important role of allowing the interviewees to follow websites, Facebook pages, and Instagram accounts dedicated to Islam and to exchange ideas with like-minded people. In the next sections, we will explore the role of Instagram in the lives of these Muslim women.

\section{Instagram as a Connecter: Opportunities of Instagram for Muslim Women}

The interviewees shared that they use Instagram for a variety of reasons, including keeping in contact with friends and romantic interests, planning travels, sharing creative and professional interests (photography, fashion, videography, architecture, cooking, fashion, and make-up), and creating business opportunities connected with such interests. While these activities are common among Instagram users, the respondents often connected them to their upbringing and background. For instance, they post pictures of Pakistani or Moroccan food and dresses, or write posts in Turkish, Arabic, and Bosnian. The interviews also focused on the different features of 
Instagram: while the Instagram wall, where the pictures stay permanently, is mostly used for posting high-quality images and videos, Instagram stories, which disappear after twenty-four hours, tend to be employed for sharing playful and informal images. Because of the short span of the Instagram stories, respondents feel freer to not appear "perfect" in the pictures and videos they post. Interestingly, many interviewees use stories also to talk about their faith and to raise awareness of religious-related causes.

According to the respondents, Instagram can have both positive and negative characteristics. A positive feature of the app is that they can follow other Muslim women that inspire them and present a type of Islam they recognize as their own. Several Muslim influencers combine religious practices with Western neoliberal culture, challenging the boundaries of what is considered fashionable and modest (Kavakci \& Kraeplin, 2016; Peterson, 2020). Hence, many of the interviewees said that they enjoy following Muslim influencers who try to counteract certain stereotypes about Islam. In particular, they consider it positive to see Muslim women on Instagram being successful in finding professional opportunities by modeling, creating clothing brands, or collaborating with fashion companies, careers that have traditionally excluded them. Furthermore, Instagram can create more awareness about the everyday practices and lives of Muslim women:

Indirectly, as a Muslim woman, you also get a stage, because if other Moroccan or Muslim women with a hijab become very well known as an influencer in a certain part of the world, and I visit that place on a vacation, it won't be such a culture shock for them, because they have seen it on their Instagram feed, you know? (BELLA, 25 YEARS OLD, HOOFDDORP)

Even if the women interviewed in this study are not influencers themselves, they feel like the popularity of other Muslim women on Instagram helps them be more readily accepted in different parts of the world. As Muslim women are rarely represented in European pop culture and so-called mainstream media, having some of them gaining popularity on Instagram is a way of creating more awareness about diversity and hybrid identities. Together with normalizing the role of Muslim women in fashion and business, Instagram also provides people with possibilities for religious education. Indeed, some of the interviewees described sharing inspirational Quran verses, educational facts, and Islamic practices. Regarding this aspect, Fayza says:

I am a Sunni Muslim, and there was this account that was focused on Shia Muslims, and they had this journey to Karbalah (Iraq), and we as Sunnis 
hear all these things about Shias, and sometimes they are incorrect. And then you think alright, I want to know what the deal really is. So, I followed that account and I saw that whole journey and I thought it was amazing. And I thought, you know, there are so many misconceptions and so many things of which you think "why is this being said and why is hate being spread in media?" But then you follow such an account and you stumble upon new things. And that is actually nice. So, I see Instagram as a connecter, and you just get to know people who you would not have met without social media. (FAYZA, 24 YEARS OLD, THE HAGUE)

This quote shows how Instagram can be useful in not only making non-Muslims more aware of Muslim women's everyday lives, but also connecting Muslims with other people of the same faith. In this case, Fayza could correct some of her misconceptions about Shia Islam by following an Instagram account. By transcending geographical boundaries, Instagram is a "connector" that can challenge stereotypes and generalizations. It is for this reason that some of the interviewers try to actively create counternarratives about Islam on their Instagram accounts, showing, for instance, that Muslim women are not oppressed, and that they do not adhere to any dangerous ideology. Mona explains this potential of Instagram as follows:

In my stories I sometimes mention Islam or, for example, two days ago I shared a post about a non-profit organization that helps Syrian refugees, and then I said with that "it is now Ramadan, and the entire Islamic Ummah is now busy giving back," so in that sense, I use it to be a kind of advocate for Islam, and kind of, place it in a good light... instead of everything that is said on the news. (MONA, 20 YEARS OLD, ROTTERDAM/ PURMEREND)

With this example, Mona shows how Instagram narratives can provide a different story about Islam. While Islam is often talked about negatively on the news, Mona tries to show the positive aspects of her faith, such as performing charity during Ramadan. In this way, Muslim women who are not influencers can also contribute to counteracting stereotypes and connecting with people that might have misconceptions about Islam. However, while religion is an important aspect of life for the majority of the interviewees, not all of them are comfortable sharing religious information on their Instagram accounts. For some of them, religion is a deeply personal choice, and Instagram is not considered an appropriate venue for certain narratives. For instance, Sara explains that she shares pictures of clothes from her family's country of origin, but she 
keeps her religion personal (Sara, 26 years old, Rotterdam). Even if religion, culture, and ethnicity are often entangled, as mentioned in the previous section, they can be shown in different ways on Instagram. In Sara's experience, ethnicity is conceptualized as materially present in pictures of clothes, accessories, and one's home country, while religion is more abstract and private. The interviewees' usage of Instagram shows that they have a precise understanding of their agency in creating their own stories and negotiating their identity. The choice of not talking about religion on Instagram might also be linked to some perceived negative characteristics of the platform, which we will discuss in the next section.

\section{A Lot of People Watching: Constraints of Instagram for Muslim Women}

While Instagram can offer opportunities for positive representations of Muslim women and Islam, some of the interviewees are also aware of its potential dangers. In particular, they mentioned that the app can pressure them to be perfect. On the one hand, they need to perform the image of the perfect Muslim woman within their communities by showing an appropriate religious behavior, and on the other hand, they face unattainable "Western" beauty standards that urge them to reflect on their appearance. Concerning the pressure of being perfect within their Muslim communities, two respondents talked about "expose accounts," which are accounts that publicly criticize Muslim women for posting about activities that are considered inappropriate, such as dancing to certain music or being dressed in a supposedly "non-modest" way. This shows how Instagram can also become a space of surveillance, where Muslim women feel under constant scrutiny and might be prevented from freely posting pictures and narratives about their daily lives. It is for this reason that some of the respondents reported not wanting to post information about their significant others. Because of the religious and cultural expectations of only dating partners with the intention of marrying them, some of the interviewees prefer to keep their dating life private and not mention it on Instagram:

I never posted my relationships on Instagram, because sometimes they do not last long. So, if I would have posted that every time, people would have thought I went through a whole laundry list. Even though, in reality, it is really not that bad. But, to me it's like, when I am engaged, and I know for sure, this one is going to marry me, then I will do it. Not that I am hiding anything, if you would ask me. But it's just that on social media, people can keep evidence. They can take screenshots and forward it. (MIDA, 26 YEARS OLD, ROTTERDAM) 
In her interview, Mida showed awareness that the public character of Instagram may allow people to save and use personal stories against her. Mida also feels the pressure of keeping her dating life private because of the negative reputation that can be attached to women with several partners. The necessity of conforming to a certain moral imperative is not always so strong in everyday life, but becomes more urgent when it comes to social networks, where rumors and assumptions can spread more easily. It is important to notice, however, that not all interviewees had the same experiences. Some post pictures with significant others, while others refrain from doing so even if they are engaged or married and therefore not doing anything that can be considered morally wrong. This is a tendency which arguably also exists among non-Muslims, that is, selectively using Instagram to post only certain information about one's private life.

Similarly, some respondents also refrain from posting pictures of themselves that are too revealing. Interviewees, including those who do not wear a veil, often reported selecting pictures with clothes covering their upper arms, chest, and legs. Several respondents also mentioned not posting pictures in their bikini, even if they wear it on the beach, to protect their privacy and because they are not comfortable sharing such images. Also in this case, this choice is usually not directly connected to religion but also to the fear that people, particularly men, can screenshot and keep their images, and that the app can kindle negative judgment from followers, family members, and peers.

The pressure of conforming to certain beauty standards arguably affects all Instagram users, but it can be particularly harmful to Dutch Muslim women who may look different from women that are traditionally considered "beautiful." Mona, for instance, criticizes certain Instagram influencers:

They post nothing more than pictures where they look good. And I think that everyone deals with this, it is not just a special case for me, but I think that people are just constantly bombarded with pictures of people who look perfect, and that creates a negative self-image. And in that sense, I also have thought "why do I not look like that?" and especially because, mostly, successful influencers are blond girls with petite bodies, and I do not have that, I am not blond, and that can be pretty destructive. (MONA, 20 YEARS OLD, ROTTERDAM/PURMEREND)

In this case, Mona is aware that her physical aspect can mark her as "other" to Dutch and Western society. As Sara, mentioned in the previous section, was considered to be pretty "for a Pakistani," Mona also explains that so-called 
Western beauty standards are often tied to whiteness and blondness. Some respondents lamented that algorithms continue to show them images of women they cannot relate to, and that Instagram seemingly reproduces some racist logics by welcoming and celebrating certain bodies more than others. Interestingly, many interviewees criticized influencers for lacking authenticity and for perpetuating unrealistic body images, but this criticism is never addressed to Muslim influencers. As mentioned above, Muslim influencers are usually described as successful and inspirational, even if they also perpetuate certain ideas of femininity and social class status (Peterson, 2020; Waninger, 2015). This is probably because the interviewees can relate more to Muslim influencers, who are therefore perceived as "authentic."

The interviews suggest that Dutch Muslim women often feel the pressure of conforming to certain norms, either to prove that they are integrated with Dutch society or to avoid criticism from other Muslims. However, their skin color or their hijabs may make them a perpetual "other" to the Dutch culture. Instagram can constitute an online space where hybrid identities can be performed in a way that allows agency and comfort. While their aspect is questioned in their everyday lives, Muslim women can choose to follow influencers that look like them and help counteract stereotypes about Islam. At the same time, they have the agency of showing themselves and their bodies at the level of their own comfort, for both religious and personal reasons, and can avoid following influencers whose bodies are different than their own. In this respect, Instagram is a "third space" (Pennington, 2018) that presents both opportunities and constraints, and in which Dutch Muslim women constantly negotiate their visibility between the imperative of conforming to Dutch society and the surveillance of Muslim communities.

\section{Discussion and Conclusion}

The article explored the digital media practices of young Dutch Muslim women, with a focus on Instagram. We discovered that these women use Instagram to create narratives that try to capture their complex identities. In so doing, they show how culture, ethnicity, and identity are entangled. The article discussed how Internet platforms such as Instagram, as noted in some previous studies (Kavakci \& Kraeplin, 2016; Peterson, 2020; Wheeler, 2014), can allow Muslim women to take control of their identity narratives and challenge existing stereotypes. However, this study also shows that these opportunities go together with the awareness that Instagram is a platform where women's bodies and actions can be policed and criticized. Therefore, it is important to explore the 
Internet practices of Muslim women by critically weighing both the potential and the negative aspects of digital spaces.

The study was performed through interviews, a method that has the advantage of capturing the experiences and meaning-making practices of the respondents even when they are not directly visible from their digital media narratives. The sample had some limitations: we included in the study only women who are educated and speak Dutch. A venue for further research would be to explore women who came to the Netherlands as adults, who belong to different age groups, or who live in other areas of the country. Furthermore, while the claims we make are arguably applicable to Internet practices in general, we focused on Instagram because it is one of the most-used platforms among young people and it allows users to create visual narratives and gain popularity by becoming influencers. However, other studies might explore how Muslim women use other social media platforms, such as YouTube, Facebook, or TikTok. It is also important to notice that some interviewees addressed the notion of beauty standards in relation to ethnic identities, both on Instagram and within society in general, something that future research can also address. With our interviews, we were able to find some interesting data about the use of Instagram by young Dutch women, and we reached three main conclusions.

First, we found that the interviewees had similar experiences in negotiating their faith and family culture within Dutch society, but they developed individual approaches to their everyday experiences and Instagram usage. While all respondents discussed hybrid practices and identities, some celebrated their multiculturalism and others felt discriminated against. Hybridity, in this context, is often not only a natural response to the coexistence of various cultures but also a surviving mechanism of the imperative to adapt to the Dutch culture. Part of this mechanism also negotiates visual appearances, both online and in everyday settings: visible signs of "otherness," such as darker skin or a veil, can trigger discrimination and racism. It is probably for this reason that the interviewees choose to show only certain aspects of their lives on Instagram, sometimes openly discussing their religion, sometimes focusing more on their ethnic background, sometimes employing religion and culture as moral guidance to decide what to share. The notion of composite habitus (Waltorp, 2015, 2020) helps to explain these strategies, but it also needs to be approached by considering women's agency in selectively posting only certain pictures and narratives. The complexity of young Muslim women's experiences is hardly generalizable, because even when they come from similar social contexts, they show considerable differences in their digital media use.

Second, the interviews suggest that Instagram is considered as a space where only certain aspects of "offline" experiences should be shared. Rather 
than an extension of everyday life, Instagram is a venue where one's identity is performatively created and made visible through a set of strategies. While religion, ethnicity, and migration background are often entangled, religion is sometimes considered on a different level than ethnicity because it is a very personal topic and indeed deemed inappropriate for a space such as Instagram. These choices are motivated by various factors determined by both the characteristics of the app and young Muslim women's experiences, such as the imperative of appearing beautiful to gain popularity, the fear of being judged by family members and peers, or the willingness to give a certain image of their faith. In this sense, Instagram can be considered as a third space (Pennington, 2018) where women can exercise agency in deciding what they wish to share and in creating narratives that are different from those surrounding them in their everyday lives. This third space can challenge stereotypes about Islam and help negotiate religious identities because it allows for a selective performance that is based on offline experiences but also unique to the platform.

Third, Islam was mentioned more explicitly in relation to the opportunities of Instagram rather than its constraints. Several interviewees, indeed, said that they talk about religion on Instagram or follow Muslim influencers, and they enjoy using the app to see pictures they can relate to. However, Instagram also has some negative aspects, such as allowing the possibility of creating "expose accounts" against Muslim girls. The interviews suggest that Islam is not only constituted by material and visible practices, such as veiling, but exists also in an implicit form in everyday moral choices and norms as well as private feelings and experiences. Even if Islam can be readily associated with positive representations, it is important to explore the approach to digital practices of Muslim women by also paying attention to the less visible pressure that they might experience because of their faith. In this study, we focused on a minority that is often marginalized within society, young Dutch Muslim women. By looking at the diversity of their experiences in negotiating hybrid cultures, considering their agency in finding new spaces of identity performances, and exploring Islam also as a set of values and norms that may condition their behaviors, it is possible to reach a greater understanding of the complexity of young Dutch Muslim women's lives.

\section{Acknowledgements}

We wish to thank Dr. Isabel Awad Cherit for giving comments on the thesis of the first author, on which this article is based. We are also grateful for the 
feedback of the two anonymous reviewers. The first author wishes to thank Narmina Telmann and Aida Alieva for the constant support and spirit of positivity throughout the process of this thesis.

\section{References}

Allen, C. (2015). "People Hate You Because of the Way You Dress": Understanding the Invisible Experiences of Veiled British Muslim Women Victims of Islamophobia. International Review of Victimology 21(3), pp. 287-301. https://doi. org/10.1177/o269758015591677.

Asad, T. (2003). Formations of the Secular: Christianity, Islam, Modernity. Stanford: Stanford University Press.

Becci, I., Burchardt, M., and Giorda, M. (2017). Religious Super-diversity and Spatial Strategies in Two European Cities. Current Sociology 65(1), pp. 73-91. https://doi. org/10.1177/oo11392116632030.

Bhabha, H. K. (1994). The Location of Culture. London: Routledge.

Bittman, M., Rutherford, L., Brown, J., and Unsworth, L. (2011). Digital Natives? New and Old Media and Children's Outcomes. Australian Journal of Education 55(2), pp. 161-175. https://doi.org/10.1177/0o0494411105500206.

Blystone, D. (2020, June 6). The Story of Instagram: The Rise of the \#1 Photo-sharing Application. Investopedia. https://www.investopedia.com.

Bourdieu, P. (1990). Structures, Habitus, Practices. In: P. Bourdieu, ed., The Logic of Practice, Cambridge: Blackwell Publishers.

Boy, J. D., Uitermark, J., and Wiersma, L. (2018). Trending \#hijabfashion: Using Big Data to Study Religion at the Online - Urban Interface. Nordic Journal of Religion and Society 31(o1), pp. 22-40. https://doi.org/10.18261/issn.189o-70o8-o1-02.

СBs. (2020). Hoeveel mensen met een migratiachtergrond wonen in Nederland? [How many people with a migration background live in the Netherlands]? Statistics research report. https://www.cbs.nl.

Doomernik, J. (2017). The Uninvited Migrant, the "Autochtoon" and the "Allochtoon" in the Netherlands. In F. Decimo and A. Gribaldo, eds., Boundaries Within: Nation, Kinship and Identity among Migrants and Minorities. Cham: Springer, pp. 37-52. https://doi.org/10.1007/978-3-319-53331-5_3.

Echchaibi, N. (2013). Muslimah Media Watch: Media Activism and Muslim Choreographies of Social Change. Journalism 14(7), pp. 852-867. https://doi. org/10.1177/146488491347836o.

Evolvi, G. (2017). Hybrid Muslim Identities in Digital Space: The Italian blog Yalla. Social Compass 64(2), pp. 220-232. https://doi.org/10.1177/oo37768617697911. 
Frisina, A. (2010). Young Muslims' Everyday Tactics and Strategies: Resisting Islamophobia, Negotiating Italianness, Becoming Citizens. Journal of Intercultural Studies 31(5), pp. 557-572. https://doi.org/10.1080/07256868.2010.513087.

Hanna, P. (2012). Using Internet Technologies (Such as Skype) as a Research Medium: A Research Note. Qualitative Research 12(2), pp. 239-242. https://doi. org/10.1177/14687941114266o7.

Hashmi, U. M., Rashid, R. A., and Ahmad, M. K. (2020). The Representation of Islam within Social Media: A Systematic Review. Information, Communication \& Society o(o), pp. 1-2o. https://doi.org/10.108o/1369118X.2020.1847165.

Hoover, S., and Echchaibi, N. (n.d.) Media Theory and the "Third Spaces of Digital Religion." Working paper. https://www.researchgate.net/publication/ 287644204_The_Third_Spaces_of_Digital_Religion.

Kavakci, E., and Kraeplin, C. R. (2016). Religious Beings in Fashionable Bodies: The Online Identity Construction of Hijabi Social Media Personalities. Media, Culture \& Society 39(6), pp. 850-868. https://doi.org/10.1177/o163443716679031.

Knott, K., Krech, V., and Meyer, B. (2016). Iconic Religion in Urban Space. Material Religion 12(2), pp. 123-136. https://doi.org/10.108o/17432200.2016.1172759.

Kumara, H. I. G. C., and Jayawardhana, R. a. W. D. (2018). International Beauty Pageants and the Construction of Hegemonic Images of Female Beauty. Sri Lanka Journal of Social Sciences 41(2), pp. 123-136. https://doi.org/10.4038/sljss. v41i2.7699.

Leurs, K., Midden, E., and Ponzanesi, S. (2020). Digital Multiculturalism in the Netherlands: Religious, Ethnic and Gender Positioning by Moroccan-Dutch Youth. In: M. Diez Bosch, A. Melloni, and J. L. Micò Sanchez, eds., Perplexed Religion. Barcelona: Blanquerna School of Communication and International Relations, pp. 103-122. http://www.obsblanquerna.com/perplexed-religion-3/.

Midden, E., and Ponzanesi, S. (2013). Digital Faiths: An Analysis of the Online Practices of Muslim Women in the Netherlands. Women's Studies International Forum 41, pp. 197-203. https://doi.org/10.1016/j.wsif.2013.07.012.

Pennington, R. (2018). Social Media as Third Spaces? Exploring Muslim Identity and Connection in Tumblr. International Communication Gazette 8o(7), pp. 620-636. https://doi.org/10.1177/1748048518802208.

Peterson, K.M. (2016). Beyond Fashion Tips and Hijab Tutorials: The Aesthetic Style of Islamic Lifestyle Videos. Film Criticism 40 (2). https://doi.org/10.3998/ fc.13761232.0040.203.

Peterson, K. M. (2020). The Unruly, Loud, and Intersectional Muslim Woman: Interrupting the Aesthetic Styles of Islamic Fashion Images on Instagram. International Journal of Communication 14, 20. 
Postill, J., and Pink, S. (2012). Social Media Ethnography: The Digital Researcher in a Messy Web. Media International Australia 145(1), pp. 123-134. https://doi.org/10.117 7/1329878X1214500114.

Prokopiou, E., Cline, T., and de Abreu, G. (2012). Rethinking Ethnic Minority Young People's Participation in Multiple Sociocultural Contexts and its Impact on their Cultural Identities. In: E. Hjörne, G. van der Aalsvoort, and G. de Abreu, eds., Learning, Social Interaction and Diversity: Exploring Identities in School Practices. Rotterdam: Sense Publishers, pp. 35-52. https://doi.org/10.1007/978-94-6o91-8o3-2. Ross, S. (2019). Being Real on Fake Instagram: Likes, Images, and Media Ideologies of Value. Journal of Linguistic Anthropology 29(3), pp. 359-374. https://doi.org/10.111/jola.12224.

Schmeets, H. (2018, October). Wie is religieus en wie niet? [Who is religious and who is not?] Statistics research report. https://www.cbs.nl.

Silvestrini, M. (2020). "It's Not Something I Can Shake": The Effect of Racial Stereotypes, Beauty Standards, and Sexual Racism on Interracial Attraction. Sexuality \& Culture 24(1), pp. 305-325. https://doi.org/10.1007/s12119-019-09644-o.

Szulc, L. (2019). Profiles, Identities, Data: Making Abundant and Anchored Selves in a Platform Society. Communication Theory 29(3), pp. 257-276. https://doi.org/10.1093/ ct/qtyo31.

van Driel, L., and Dumitrica, D. (2020). Selling Brands While Staying "Authentic": The Professionalization of Instagram Influencers. Convergence: The International Journal of Research into New Media Technologies 27(1), pp. 66-84. https://doi.org/ $10.1177 / 1354856520902136$.

van Sterkenburg, J., Peeters, R., and van Amsterdam, N. (2019). Everyday Racism and Constructions of Racial/ Ethnic Difference in and through Football Talk. European Journal of Cultural Studies 22(2), pp. 195-212. https://doi.org/ 10.1177/1367549418823057.

Vis, F., van Zoonen, L., and Mihelj, S. (2011). Women Responding to the Anti-Islam Film Fitna: Voices and Acts of Citizenship on YouTube. Feminist Review 97(1), pp. 110-129. https://doi.org/10.1057/fr.2010.29.

Waltorp, K. (2015). Keeping Cool, Staying Virtuous: Social Media and the Composite Habitus of Young Muslim Women in Copenhagen. MedieKultur: Journal of Media and Communication Research 31(58), p. 49. https://doi.org/10.7146/mediekultur. v31i58.19373.

Waltorp, K. (2020). Why Muslim Women and Smartphones: Mirror Images. London: Routledge.

Waninger, K. (2015). The Veiled Identity: Hijabistas, Instagram and Branding in the Online Islamic Fashion Industry. Master's Thesis, Women's, Gender, and Sexuality Studies, Georgia State University. https://scholarworks.gsu.edu/wsi_theses/48/. 
Wethington, E., and McDarby, M. L. (2015). Interview Methods (Structured, Semistructured, Unstructured). In: S. K. Whitbourne, ed., The Encyclopedia of Adulthood and Aging. Hoboken, NJ: John Wiley \& Sons, pp. 1-5. https://doi. org/10.1002/9781118521373.wbeaa318.

Wheeler, K. R. (2014). Remixing Images of Islam. The Creation of New Muslim Women Subjectivities on YouTube. Online - Heidelberg Journal of Religions on the Internet 6 , pp. 144-163. https://doi.org/10.11588/rel.2014.0.17364. 